\title{
25 Years of the Journal of Fluorescence
}

\author{
Chris D. Geddes ${ }^{1}$
}

Published online: 10 February 2016

(C) Springer Science+Business Media New York 2016

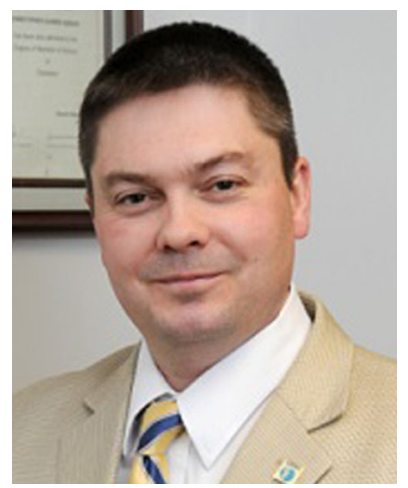

March 2016 marks the 25th anniversary of the founding of the Journal of Fluorescence, JoFl. Over this quarter century, the journal has earned a well-deserved reputation as the prominent fluorescence-based journal in the world today.

Since 2001, the journal has published 2375 articles, contributed by over 6538 authors, which have been cited a remarkable 18,066 times. The most cited article today is an editorial I wrote entitled "Metal-Enhanced Fluorescence" in 2002, which today has been cited some 376 times.

In the early 2000's the journal transitioned to an allelectronic publishing platform. I remember it well, as when I inherited the journal from my predecessor in 2002, I set about the mammoth task of pushing for the transition. Many of you will remember these old days, when we all sent hard copies of

Chris D. Geddes

geddes@umbc.edu

1 Institute of Fluorescence, University of Maryland Baltimore County, Columbus Center, 701 East Pratt St., Baltimore, MD 21202, USA

a manuscript by mail to the editorial office, which were then in turn sent out to review, also by mail. My first task in 2002 was making this review process one which was underpinned by email and attaching manuscripts to e-mails as attachments. Even this was an arduous task as many different forms of media and disk types were being used, with some manuscripts even being typed on a typewriter, figures hand drawn and sometimes also photographs as figures. Another big problem laid in the peer review process and locating suitable reviewers, as there was no database at that time. These were the days when many researchers and faculty did not have online University lab pages. To address the need for a database of fluorescence workers contact details and a listing of their particular expertise, I launched the Who's Who in Fluorescence annual volume (in 2003), which published the names, contact details and the specialty of workers. The volume was a huge success with hundreds of entries and researchers happy to update their information yearly. The volume ran from 2003 to 2009. The volume's business model was one underpinned by advertising revenue, where fluorescence-based companies placed ads which in turn offset the cost of the volumes' production. The entire volume was typeset by Caroleann Aitken, which was a big undertaking and without her dedication, the volume would not have been a success. The Who's Who in Fluorescence turned out to be a very successful volume, with thousands of copies being sold through Amazon.com, as well as disseminated freely at international conferences, such as MAFS. The price point was specifically set below $\$ 20$ at $\$ 19.99$, to allow the volume to be distributed freely to federal employees, such as NIH and NSF staff (gifting regulations). Armed with an e-mail based peer-review process and a large database of fluorescence-workers, the Journal grew significantly over the next few years. With a very strong and 
internationally recognized editorial board, the journal published numerous high impact thematic issues.

By the mid to late 2000's we had transitioned to a webbased submission system (Editorial Manager), and I remember the JoFl being relatively early in the process as compared to other major journals at the time. The Who's Who in Fluorescence volume had grown significantly and so we were well positioned for web-based manuscript processing after the database had been uploaded into the Journal of Fluorescence's web-based editorial manager system. (https://www. editorialmanager.com/jofl/default.aspx). This was a pivotal transition point for the JoFl. The web-based system, which is still in place today, allowed the simultaneous review of dozens of articles, and most importantly, there were considerably less e-mails in my inbox ! All back issues of the journal, back to 1991, were subsequently digitized and made available online. From time to time these were open access but mostly they remained pay-per view. Since 2005, more than 940,000 articles have been downloaded from the Journals website, from the 25 volumes, 119 issues available.

Today, the Journal of Fluorescence is thriving and the key journal of the Fluorescence community, with ever improving statistics year after year. For example, we have seen the review time (from submission to first editorial decision) drop to and remains at roughly 40 days. This is in stark contrast to the early 2000's, where this time was about 3-6 months. After acceptance articles are published today on line an average 18 days later. With a rapid publication date and a streamlined manuscript submission process, the journal is well-positioned to tackle the challenges ahead in the next 25 years.

In closing I would like to thank a great many people for their help and many contributions to the Journal. The editorial board has done a superb job in years passed and I appreciate all your comments and guidance. A great many reviewers have dedicated time and effort to reviewing over two thousand accepted manuscripts, a great many more rejected (rejection rate $>50 \%$ ). The authors have supplied excellent content to the Journal and we hope they will continue to do so. Finally I would like to thank Springer, and the numerous journal editors and administration staff at Springer I have worked with over the years, such as Aaron Johnson, Aleta Kalkstein, Christina Dzikowski and Meran Lloyd-Owen, to name but just a few, for their help, advice and for helping me to grow the journal, I thank you all.

Dr Chris D. Geddes, Ph.D., FRSC,

Professor

Editor-in-Chief: The Journal of Fluorescence

January 28th 2016. 